Article

\title{
Transport Infrastructure and Social Inclusion: A Case Study of Tourism in the Region of Gilgit-Baltistan
}

\author{
Asif Hussain *, David Fisher and Stephen Espiner \\ Faculty of Environment, Society and Design, Lincoln University, Lincoln 7647, Canterbury, New Zealand; \\ E-Mails: asif.hussain@lincolnuni.ac.nz (A.H.), david.fisher@lincoln.ac.nz (D.F.), stephen.espiner@lincoln.ac.nz (S.E.) \\ * Corresponding author
}

Submitted: 29 June 2017 | Accepted: 16 October 2017 | Published: 28 December 2017

\begin{abstract}
Until the building of the Karakorum Highway (1958-78), the region of Gilgit-Baltistan, Pakistan, was extremely isolated, thus preserving distinct cultural traits. The few tourists accessing the area were primarily experienced mountaineers. The highway was established to provide a land link with China, principally as a result of turbulent geo-political rivalry. Once built, however, the road created a connexion to the outside world and allowed for many more visitors to the region. Whilst the road was not built with tourism in mind, it allowed easier access for tourists and necessitated the development of a service sector to provide for those using the road. As a consequence, a once subsistence and self-reliant economy became monetised, and modern consumer goods were introduced to the region. Increased access and mobility has facilitated change in the Gilgit-Baltistan, contributing to a degree of social inclusion not previously possible. Whilst there are multiple drivers of change observed here, tourism has provided an important means by which some of the more profound changes have occurred. Local people have adapted their livelihoods to the new, monetary economy resulting in a decline in traditional agricultural practices. More importantly, however, tourism has enabled the outside world to enter into the consciousness of local people. Visitors have become conduits of change and the world is now viewed via technologies made possible by the spoils of tourism. The road has also allowed for much easier movement of local people out of and back to Gilgit-Baltistan, thereby facilitating increased social inclusion with the wider world.
\end{abstract}

\section{Keywords}

development; Gilgit-Baltistan; mobility; Pakistan; road; social inclusion; tourism; transport

\section{Issue}

This article is part of the issue "Regional and Urban Mobility: Contribution to Social Inclusion", edited by Janet Stanley (University of Melbourne, Australia) and John Stanley (University of Sydney, Australia).

(C) 2017 by the authors; licensee Cogitatio (Lisbon, Portugal). This article is licensed under a Creative Commons Attribution 4.0 International License (CC BY).

\section{Introduction}

With the growth of technology and increased levels of wealth, social systems have become more open. In the past, it was relatively uncommon for people to move far from where they lived. Industrialisation resulted in urban drift and people became more integrated into monetary economies (Hussain, 2017). In some parts of the world, the opportunity to move elsewhere was also restricted by physical geography. Despite a wide variety of social structures, isolated groups relied on all the inhabitants for survival. Even someone at the bottom of the social hierarchy had a function that helped the community to maintain itself. At the same time, most members of such societies were excluded from participating in the world beyond the immediate environs.

Adopting an entirely qualitative approach, this study explores the changes that have occurred in selected communities in Gilgit-Baltistan, a once isolated area that was afforded much easier access to the outside world by the building of a highway, opened in 1978. By enhancing the opportunities for spatial mobility, members of a commu- 
nity can simultaneously reduce their levels of inclusion within the home community and increase inclusion with the outside world. This article demonstrates how the integration of isolated regions with the outside world is facilitated through the development of transportation infrastructure, and how such infrastructure has monetised societies and resulted in both physical and digital inclusion in the re-ordering of those societies. People become involved in the social world beyond their geographic location in three primary ways. First, by physically entering it through travel away from the place of origin. Second, people from outside can migrate or enter the local community more easily bringing outside ideas and goods with them. Third, by integrating with the outside world, a community can move from a subsistence economy to a monetised one, which enables members to purchase goods, such as televisions, radios and mobile telephones which provide easy access to information and new ideas from places elsewhere. What is important about consumer goods is not their ownership but access to the levels of inclusion they allow. A whole community may have access to these goods even though only some members of the community own them.

This article examines the issue of social inclusion in Gilgit-Baltistan using factors including income and employment, isolation, political participation and citizen- ship, and access to transport, education, healthcare, goods and services (Kenyon, Lyons, \& Rafferty, 2002). What will be shown here is that social systems have undergone a profound, externally generated, change. How individuals respond to those changes will impact on the benefits, or otherwise, that they receive and their levels of social inclusion. It will also be shown that social inclusion and exclusion may, in some circumstances and places, not follow the usual understanding of social inclusion.

\section{Research Site}

The exemplar used here is the region of Gilgit-Baltistan, (see Figure 1), at the junction of the Karakoram, Himalaya, Hindukush, and Pamir mountain ranges. The region, more than 70,000 square kilometers in area, was formerly known as Gilgit Agency or Northern Areas, and remains a disputed territory claimed by both Pakistan and India. Gilgit-Baltistan is administered by Pakistan. The isolated nature of the area and its inhabitants make it unique as every valley has distinct features (Khalid, 2006).

Geopolitical circumstances in the latter half of the 20th century resulted in the construction of the Karakoram Highway-a high mountain road through this

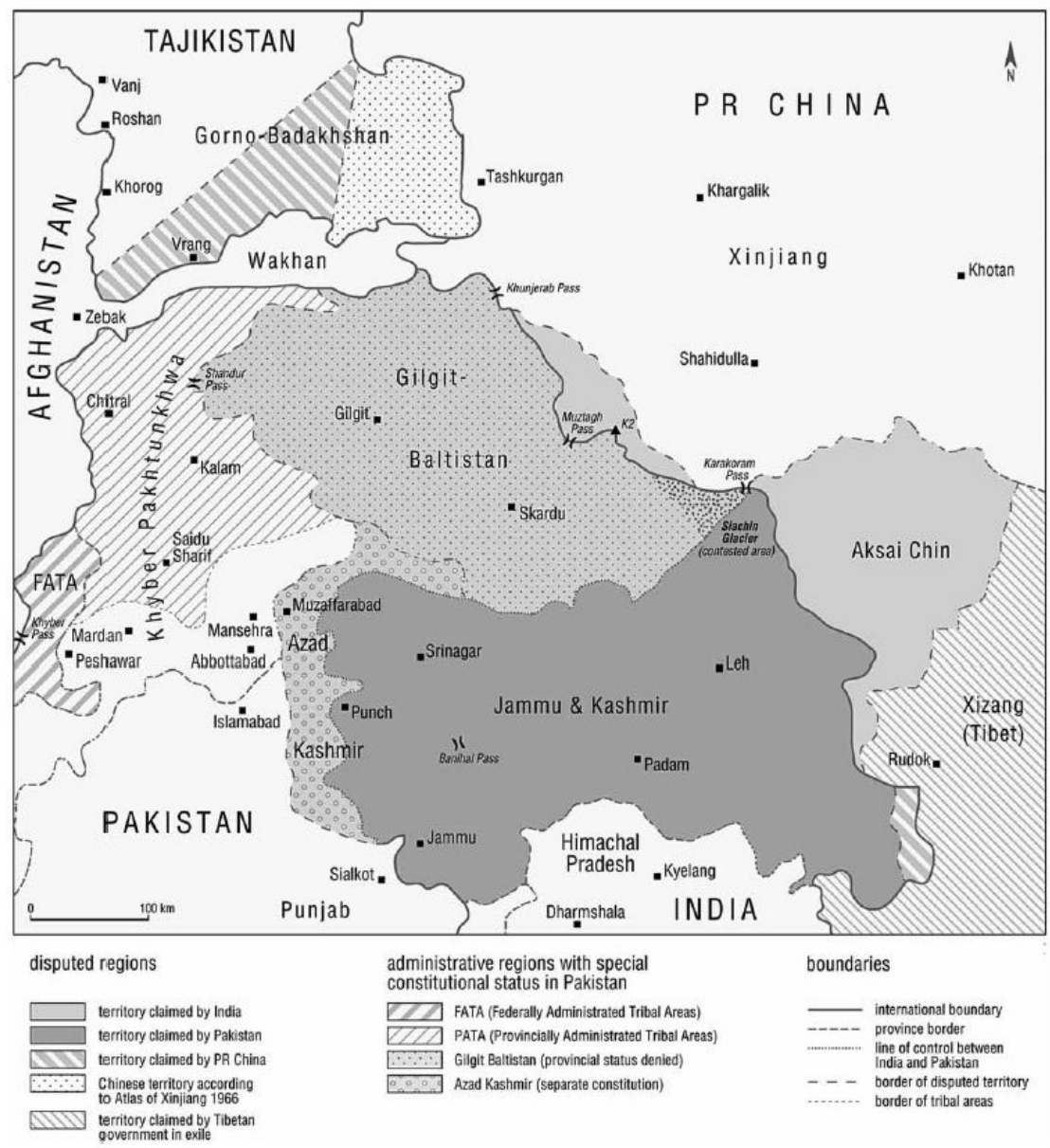

Figure 1. Disputed territories and constitutional peculiarities in Western High Asia (Source: Kreutzmann, 2015). 
remote terrain-followed by political reforms, which rapidly increased the population (Kreutzmann, 1991, 2015). According to the census of 1998 (Pakistan), the population of Gilgit-Baltistan was $8,720,000$. The census of 2017 (Pakistan) recorded a population of 14,920,000 [unofficial results], an increase of $71 \%$ with a growth rate of 3.5\% per annum (Ali, 2017).

The highway not only allowed for the movement of local people but also access for tourists, both domestic and international. The region holds much ecological, archaeological and cultural diversity which makes it popular with visitors. Gilgit-Baltistan used to receive more than 100,000 international tourists annually (before 9/11), but this number decreased to 4,524 per annum (2013) due to the wave of terrorism in Pakistan (Rana, 2014). However, there has been an increase in domestic tourist flows after political reforms in GilgitBaltistan followed by the completion of the Karakoram Highway improvement project in 2015. For instance, annual domestic tourist inflow increased from 50,000 per annum (on average), before 2014 (Rana, 2014), to 600,000 per annum in 2015 and an expected tourist inflow of over 1,000,000 in 2016 (Hussain, 2016). As a result of the influx of visitors, local people who had once survived with subsistence agriculture are able to provide services for travellers and receive monetary payment, enabling them to purchase goods which have added another layer of inclusion with the outside world. The majority of international tourists who visit Gilgit-Baltistan are adventure seekers such as mountaineers and hikers. Baltistan is a hub for adventure seekers as four out of five $8000 \mathrm{~m}$ peaks in Gilgit-Baltistan (total 14 in the world) are in Baltistan.

The Karakoram Highway through Gilgit-Baltistan was constructed between 1958 and 1978, to connect Xinjiang (China) with Islamabad (Pakistan) for trade and security purposes (Kreutzmann, 2015). The opening of the Karakoram Highway has resulted in some loss of uniqueness in the area with numerous ecological and social changes due to rapid population increase and much greater dependency on external food sources (Pakistan \& IUCN, 2003). The new infrastructure has resulted in the social inclusion of isolated communities in GilgitBaltistan with the external world by providing access to transportation, including access to private cars. Conversely, it is also argued that access to transport infrastructure and private cars are the enemy of community solidarity and results in social exclusion (Barry, 1998). Such a notion of transport infrastructure development may ultimately enhance social inclusion at regional and national levels, yet may also serve to undermine social inclusion locally.

\section{The Concepts of Social Inclusion and Exclusion}

The concepts of social inclusion and social exclusion are widely recognised, however, the concepts have been vaguely defined, and understood in numerous ways
(Church, Frost, \& Sullivan, 2000; Kenyon et al., 2002; Lucas, 2012). Litman (2003, p. 2) argues that:

Social inclusion refers to people's ability to participate adequately in society, including education, employment, public services, social and recreational activities. Social exclusion refers to constraints to adequate participation.

Percy-Smith (2000) argued that an individual or a group is socially excluded if one or more of these factors is compromised.

Social exclusion is dynamic in nature and it depends on the level of social inclusion (Atkinson \& Hills, 1998). Levitas et al. (2007, p. 9) define social exclusion as:

The lack or denial of resources, rights, goods and services and inability to participate in the normal relationships and activities, available to the majority of people in a society, whether in economic, social cultural or political arenas. It affects both the quality of life of individuals and the equity of cohesion of society as a whole.

While the concepts of social exclusion and poverty share much in common, Lucas (2012, p. 106) states that social exclusion 'reaches beyond the description of poverty to provide a more multidimensional multilayer and dynamic concept of deprivation'. It is reasoned that where poverty:

implies an absolute or relative access to material welfare, social exclusion [is] a broader concept which usually implies that some people or households are not just poor but that they have additionally lost the ability to both literally and metaphorically connect with many of the jobs, services, and facilities that they need to participate fully in society. (Church et al., 2000, p. 197)

Folwell $(1999$, p. 12) argued that mostly it is not clear what researchers measure when they refer to poverty. It is important to understand, and promote citizenship, public consultation and access to policy making (Burchardt, Le Grand, \& Piachaud, 1999).

\section{Transport Infrastructure and Social Inclusion}

Physical mobility may lead to social inclusion by providing access to opportunities such as services and social networks(Kenyon et al., 2002). Hence, it is important to understand to what extent mobilities lead to social exclusion and the overall well-being of individuals (Church et al., 2000). Wachs and Kumagai (1973) identified that lack of physical mobility is a major contributor to social and economic inequality. Church et al. (2000) argue that the poorest and most transport disadvantaged segments of a society are the most socially excluded. In suburban 
areas in Australia, for instance, distance is considered to be the major barrier to economic and social inclusion (Currie, Stanley, \& Stanley, 2007). Such barriers will alienate individuals from access to education, commerce, leisure, cultural activities, health care and social welfare (Church et al., 2000). It is possible that many segments of a society may have access to transport but be socially excluded whilst others may be transport disadvantaged but socially included (Currie \& Delbosc, 2010).

The development of transport infrastructure, such as roads, can have a large impact on economies (Owen, 1959). Olsson (2009) argues that improved roads will lead to direct effects in the form of reducing travel times and costs, and improved reliability. Transport improvement stimulates and enables the use of resources rather than creating innovations (Garrison \& Souleyrette, 1996). This is done by facilitating production processes, land use, and marketing which will lead to reducing trade costs and using resources more effectively and adapting new technologies. Lakshmanan and Chatterjee (2005) argue that such facilitations will enable people to do an old thing in new ways and new techniques will emerge leading to social and economic advances. Peters (2000) states that improved transport infrastructure will benefit the whole society by reducing the cost of production and transportation as we live in a society where modern economies are not based on bulk production but, rather, rely on flexible and on-time deliveries using technological innovations.

Another concept that is closely linked with transportrelated social inclusion is tourism mobilities. Hannam, Butler, and Paris (2014) argue that the tourism industry is intimately involved with the movement of a range of materials. This concept is widely recognised and can be noticed in the work of Gill, Caletrío, and Mason (2011); Hannam (2006); Hannam et al. (2014) and Richardson (2013). Tourism mobilities encompass the movement of people, objects, intangible thoughts, use of technologies, and information across the whole world through public space (Hannam et al., 2014). Tourism is integral to economic and political development processes of everyday life (Hannam et al., 2014) because of the large scale of the movement of people, objects, and information (Oswin \& Yeoh, 2010). For instance, the increased movement of tourists in Gilgit-Baltistan is a consequence of transport infrastructure and automobilities which has created the potential for more freedom of movement for local people and connected them, both socially and economically, with the outside world (Hussain, 2017).

Furthermore, tourism mobilities can also be viewed from a geopolitical perspective in relation to a nation's foreign policy which may affect the movement of people across borders and may lead to conflicts (Hannam et al., 2014). Gilgit-Baltistan is a prime example which has witnessed many conflicts since 1947 resulting in the shutting down of the ancient trade routes between GilgitBaltistan and Kashmir and Ladakh. This has led to social exclusion, by causing the isolation of the whole region of Gilgit-Baltistan until the Karakoram Highway was built, which connected Gilgit-Baltistan with Pakistan.

Church et al. (2000) argue that the social exclusion approach to understanding transport disadvantages will assist policymakers in recognising and comprehending the multidimensional nature of the subject and the issues associated with it. This can be done by investigating seven features of transport systems which contribute to social exclusion, including physical exclusion, geographical exclusion, exclusion from facilities, economic exclusion, time-base exclusion, fear-based exclusion and space exclusion (Church et al., 2000). The real value of transport impact studies is to identify the circumstances under which various social and economic changes occur in certain areas (Olsson, 2009). In a tourism context, it is important to understand how tourism has influenced the level of access to goods and services, costs, time and seasonality factors when influencing destination communities.

\section{Digital Social Exclusion}

Helsper (2008) argued that the nature of the link between digital exclusion and social exclusion is poorly understood and there is little theoretical development in this regard. Anderson and Tracey (2001) state that people tend to dip in and out of technology, such as the internet, depending on their need and use of the technology which might result in social exclusion or social inclusion based on resource use of the digital infrastructure, access, skills, attitudes and extent of engagement with technologies. Furthermore, it is also claimed that community members, who are socially deprived, have limited access to digital resources such as information and communication technologies (ICT), i.e., the internet, which often results in advanced economies being information sources (Helsper, 2008).

Phipps (2000) argues that electronic communications are not causing social exclusion, but lack of access to such communication may have potential to exclude individuals or groups by polarisation and creating numerous divisions among people in a community. This segregation in a society is based on who has access to information, who are information rich and who are information poor (CoMPRIS, 1998, cited by Phipps, 2000).

\section{Tourism and Social Inclusion}

Tourism in the mountain communities of Nepal has transformed the functions of traditional human settlements since Nepal opened its borders in the1950s (Nepal, 2005). As one illustration of this, the Nepali census in 1981 shows that $97 \%$ of the population was dependent on agriculture. Twenty years later this dependence had dropped to $66 \%$ (MOAC, 2001). Nepal is a landlocked region which offers mountaineering, rock-climbing, adventure activities, a rich culture, biodiversity and history (Gurung, 2012). Tourism started in the 1960s af- 
ter the establishment of the international airport. Harrison (2001) argues that improved roads and other infrastructure have provided easy access and attracted international tourists. Tourist inflow has replaced traditional trade practices, subsistence farming and animal husbandry with tourism-based economies (Espiner, Stewart, \& Lama, 2017; Nepal, 2005). With an increase in numbers of international tourists, rural communities in Nepal diversified agricultural produce and are now growing more cash crops keeping in mind the taste of tourists. The number of shops and accommodation businesses that have started due to increases in the number of tourists (Gurung, 2012) has gone from 6000 in 1962 to 600,000 in 2010 (MoTCA, 2010). Before the introduction of digital/electronic communication, the only way to communicate was in person or via word of mouth, hence there was limited contact with the outside world (Gurung, 2012). Now, mobile phones and internet services are common. Gurung (2012) illustrates this with the example of the remote village of Jomsom which is now connected with the rest of the world.

In Gilgit-Baltistan, transport infrastructure has influenced and shaped livelihoods in tourism destinations such as the settlement of Hushe, the last settlement before one enters into the wilderness of the Karakoram mountain ranges in Baltistan. Host communities have diversified livelihood strategies, which include abandonment of traditional livelihood methods, and destination communities have benefited from the tourism industry in the form of electricity, phone and television facilities (Hussain, 2017). It can be argued that people who have not diversified their sources of livelihood are more vulnerable to social exclusion compared to those who have. Diverse sources of livelihood might be considered more socially inclusive. For an area such as Gilgit-Baltistan, the question of social inclusion/exclusion may not be so simple. Much depends on the level of individualism that is created by more diversified livelihood strategies. The literature on social exclusion noted above relates to levels of deprivation. It is possible to be poor but not deprived.

\section{Research Gap}

Transport-related social exclusion is a multifaceted and dynamic concept which addresses issues related to accessibility and the processes, including institutional arrangements, that limit social inclusion (Ricci, Parkhurst, \& Jain, 2016). The current research literature shows that a lack of access to transport facilities prevents access to social services such as jobs, learning, healthcare, and leisure (SEU, 2003). Further, much of the literature on social inclusion addresses concerns in the context of developed countries where the concept of transport refers to public or private transportation systems such as buses and trains. In the rural developing country context, transport infrastructure can refer to a proper walking track where riding an ox, horse or a mule is considered a luxury. In such settings, the development of simple link roads can make a huge contribution towards social inclusion by providing access to markets and diversifying livelihood opportunities. Such social inclusions may also provide access to opportunities such as jobs, education, healthcare, and leisure. Hence, there is a need to understand the social inclusion and exclusion in a developing country context and find ways to address the problem related to transport infrastructure development. It is important to understand how different strategies adopted by various segments of the society influence social inclusion or exclusion (Ricci et al., 2016).

\section{Research Methods}

Deeply rooted in participants' personal knowledge and lived experiences, qualitative research methods such as interviews and observations in natural settings have been widely used to understand the nature of livelihood, community, and culture (Denzin \& Lincoln, 2008; Patton, 2002; Ritchie, 2013; Snape \& Spencer, 2011). In the current study, empirical data were collected via semi-structured open-ended interviews. In total, 98 interviews (face to face) were conducted in Gilgit-Baltistan between January and April 2016. The fieldwork locations included Gilgit, Skardu, Khaplu, Hushe, Shigar, Askole and Islamabad. Research participants comprised nine government representatives, 28 community organisation representatives, and community leaders, 14 household heads and seven participants from tourism enterprises such as accommodation, food, transportation, activities, and tourism beneficiaries (tourists providing direct scholarships). Cultural norms necessitated that the interviews were primarily undertaken with men (95), although a small number (3) of women were included as participants. As a result of this research constraint, the current sample cannot represent the impact of change on women. Interview length varied from 30 to 60 minutes. Interviews were conducted in Urdu, Shina, Balti, and English. All interviews were recorded with the help of a digital voice recorder and then translated and transcribed. Translator services were acquired for four interviews only. The research uses pseudonyms to ensure participant anonymity. The data were analysed by dividing the empirical material into small units of meaning themes (focused coding) through the process of codification (Goulding, 2002). Axial coding was then used to find a higher level of abstraction which specifies relationships and its basis for theory construction (Spiggle, 1994). Empirical data was coded into themes such as the consequences of roading infrastructure on livelihoods, tourism and its impacts on traditional lifestyle and income sources.

\section{Results and Study Findings}

This section explains the status of social inclusion in Gilgit-Baltistan, using factors introduced by Kenyon et al. (2002), before and after transport infrastructure development. 


\subsection{Income and Employment}

Historically, in Gilgit-Baltistan, subsistence farming, animal husbandry, and barter trade were the main means of making a living. Trade was carried out on and along various branches of the ancient Silk Route-for which Gilgit had been a staging post for caravans to and from many destinations.

Adventure tourists started visiting the region in 1955-60, after the first ascent of K2 in 1954. At that time, Fokker aircraft used to operate from Rawalpindi to Skardu (Ozi, Aleem). 'Because of no roads three or four expeditions used to come. It was very difficult and dangerous for both tourists and porters. There was six days trek to Askoli [only $114 \mathrm{Km}$ away from Skardu] and they (tourists) had to carry their ration for six days' (Ozi, a household head). 'Tourists had to carry everything as there were no facilities available. Sometimes, we had to carry some 1000 loads (25kg per load)' (Hareef).

After the road was completed, the physical mobility has led to numerous job opportunities. For instance, travelling to cities to sell services increased household income. 'People used to go to Gilgit, as the road came to Gilgit first' (Aqi, a community organisation representative) and when the road came to Skardu people started going to Skardu for labouring jobs (Ajjad, Usa) and then the road came to Khaplu and now vehicles can come to Hushe.

I myself have carried $25 \mathrm{~kg}$ load from Gilgit to Hushe. I used to go to Skardu for labouring jobs....and now, the road has brought facilities to us. The road is very beneficial. (Aved, a household head)

Community leaders argue that before the road there was no concept of a job, money or wages as there was no formal government or private system to create jobs (Her, Shiq). 'I had worked as a shepherd before I went to Rawalpindi. We had to bring the muck of livestock to our homes to make fire' (Ustaq, a restaurant manager).

With the road, whoever has money can get everything they need which is how the awareness about money developed (Hmad, a private transport operator). Aja, a community leader, believes that with money, people can provide facilities and comfort their families and won't feel poor which is seen as a big change, a sentiment shared by others: 'Poor people have got jobs now and rich people continued farming which has made us all equal' (Azahir, a household head); 'Money is generated by providing services to tourists, working for a contractor and getting a job after getting an education' (Aqi, a community organisation representative).

\subsection{Isolation}

Most of the study participants recall that before the construction of the road, people moved around the region via a narrow walking track, which had been formed by repeated and prolonged use. Sometimes people had to climb a mountain, cross difficult and dangerous mountain passes and glaciers, and then cross rivers which were hazardous during the flood season because there were no proper bridges.

'When we asked our forefathers, they haven't even travelled past Khaplu [60km away] and my father has travelled as far as Skardu [150km away]' (Ulfiqar, a cook). Travelling was mainly on foot. 'Our forefathers have told us that they had to use bird feathers to wrap their feet because of blisters' (GhulamH, a community leader). People used to walk barefoot and there were no shoes. When they got blisters, they would rest after every 5-6 km. Sometimes they would stay at someone's place (Han, a private transport operator). 'It used to take 15-20 days to reach Srinagar from Khaplu and people had to carry rations on their backs...so, what would they have brought from there? People died on their way. There are many graves on the way to Kashmir' (Amal, a hotel manager).

Historically, Gilgit-Baltistan used to trade with Ladakh, Kargil, and Kashmir. There were trade routes from Skardu to Ladakh via Khaplu, Skardu to Kargil, Gilgit to Kashmir via Astore. After partition and the JammuKashmir conflict, these trade routes were shut down and the area became more isolated (Alman).

Following the establishment of the Karakoram Highway, the region of Gilgit-Baltistan was connected with communities beyond their geographically defined localities. Our participants reported that before the road 'people were confined to their place and did not know much about their surrounding areas. People used to engage in local cultures and work in the field' (Yed, household head). 'People used to suffer a lot and now we can go wherever we want to go with the help of transport' (Haikh, household representative). 'People used to wear woollen clothes and now there are so many varieties out there. Which is because of the road. Whatever fashion is being adopted [in cities] come into these markets and things have become part of local lifestyle' (Asim, a community leader). 'Now, every hour a vehicle arrives at our doorstep with groceries. It used to take three days from Khaplu to Skardu; now it takes two hours' (Hmed, a household head).

One community organisation representative argues that the biggest change resulting from the development of roading infrastructure is the change in livelihood resources, their nature, and uses.

In the old days, people's houses were close to the mountains because resources were there. People used to keep livestock, bring grass/hay, wood etc and people wanted to live close to the resource because it was easy. Since road network people started coming close to the roads, because resources started coming from here. Now, wood comes via road, flour comes via the road, grass/hay comes via road and now people have changed their living pattern. Hence the road 
has played a vital role. The importance of the road is such that it takes you close to the resource. (Hah, a non-government organisation representative)

With roads, there has been an interaction between people from cities and remote areas and people have experienced different cultures: 'We have seen changes in people, their behaviour, a way of understanding, approach, and tolerance because of interaction with other people who are more developed' (Azir, representative planning and development). Such interaction with people from other places has increased awareness about dispensaries/health clinics, schools and other community facilities. 'Some valleys were conservative and used to think that their village was the whole world' (Asool, a non-government organisation representative). Gradually, because of awareness and observing the benefits of roads people asked to extend the road to their area as wheat, which was a luxury, became available in shops because of the road (Umtaz, an engineer). Now, everyone wants to be connected with the regional, national and international market to benefit from the road (Li, government representative).

A further illustration of enlarged social inclusion for the people of Gilgit-Baltistan was observed by our respondents in the sense of curiosity and craving for learning from travellers. It is believed that 'good habits from visitors were adopted which resulted in the development of the society' (Azir, planning commission representative). This process of learning started from the time when road construction started, through meeting Chinese contractors and labourers. 'Gradually people became aware of each other's culture, food and skills and so on, which were exchanged during the whole process of the construction of a road' (Asir, representative planning, and development).

We witnessed the change right in front of us. They would not take a bath for months. If a person is standing there you could smell him. When they saw our people, our way of living, they started adopting gradually....Our canteen contractors were instructed to bring everything from down country and put it on sale for labourers. you would be amazed to know that they even bought lipstick, talcum powder etc. now, their culture is the same as any other part of Pakistanalmost the same. (Umtaz, an engineer).

Roads have increased social interaction with people from all over the region and beyond. 'Roads have opened up landlocked area otherwise people would not meet others and their ideas would not change' (Ahan).

\subsection{Political Participation and Citizenship}

During British rule (1840-1947), Gilgit-Baltistan was used by the British to keep an eye on Russian expansionism (Kreutzmann, 2004). The British governed Gilgit-Baltistan indirectly through local rulers called Raja. These Rajas were the sole authority and first point of contact to whoever wanted to access this region. According to our informants, the Raja's job was to collect taxes on agricultural produce, manage or control news and information, movement and migration and facilitate any visitors (Han, Zam, Asharat). During the Raja system, the public was not allowed to question any decision made by the Raja (Asharat). People were suppressed and were not even allowed to leave the periphery without formal permission from the Raja (Asharat, Faraz). Since the partition of the Indian-subcontinent in 1947, Gilgit-Baltistan's political status has remained in limbo due to the unresolved Kashmir issue, since 1948. Pakistan adapted and continued the princely state ruling system in Gilgit-Baltistan. In 1971, the Raja system was abolished because of political reforms in the Pakistan (Herbaz). However, citizenship for the people of Gilgit-Baltistan is denied by Pakistan and the constitution of Pakistan defines Gilgit-Baltistan as a disputed territory. Gilgit-Baltistan has no representation in the national assembly of Pakistan (Rshad, Asharat).

According to the resolution of the United Nation (UN) in 1948, both India and Pakistan were asked to withdraw their troops from both Gilgit-Baltistan and Kashmir and conduct a referendum and let people decide their fate. But both countries are reluctant to do so due to the geographic location of the area, water resources, and other natural resources. While the formation of the road did not change the political status of Gilgit-Baltistan there has been an increase in awareness about its disputed status. Many respondents commented on this disputed political status. For instance, one respondent argued that 'if Gilgit-Baltistan is not part of Pakistan then how come China became the neighbour of Pakistan? (Rashad). Many others questioned why. Pakistan is collecting royalty fees from climbing expeditions in GilgitBaltistan if the area is not part of Pakistan.

\subsection{Access to Transport, Education, Healthcare, Goods, and Services}

According to many of our informants, prior to the construction of the road, only the young and healthy could travel and bring some necessary items such as farming tools and rare consumer items such as salt. It used to take about 15 days for the return trip from Tisarto Skardu [70km] (Ida, a shopkeeper), around one month to Gilgit [250km] (Han, a private transport operator), and 40-45 days to Kargil [approximately $250 \mathrm{~km}$ ] (Adi, a porter). It was argued that 'the distance was not great but there was no proper road hence it used to take time' (Shiq, a community leader) (see Figure 2). This is because there was no transport system, no bridges which restricted people's movements and migration (Haikh, a household head). Some 'people went to Kashmir and Ladakh and saw the roads and other facilities and told people here. That is how the concept of the road came' (Anish, a household head). 


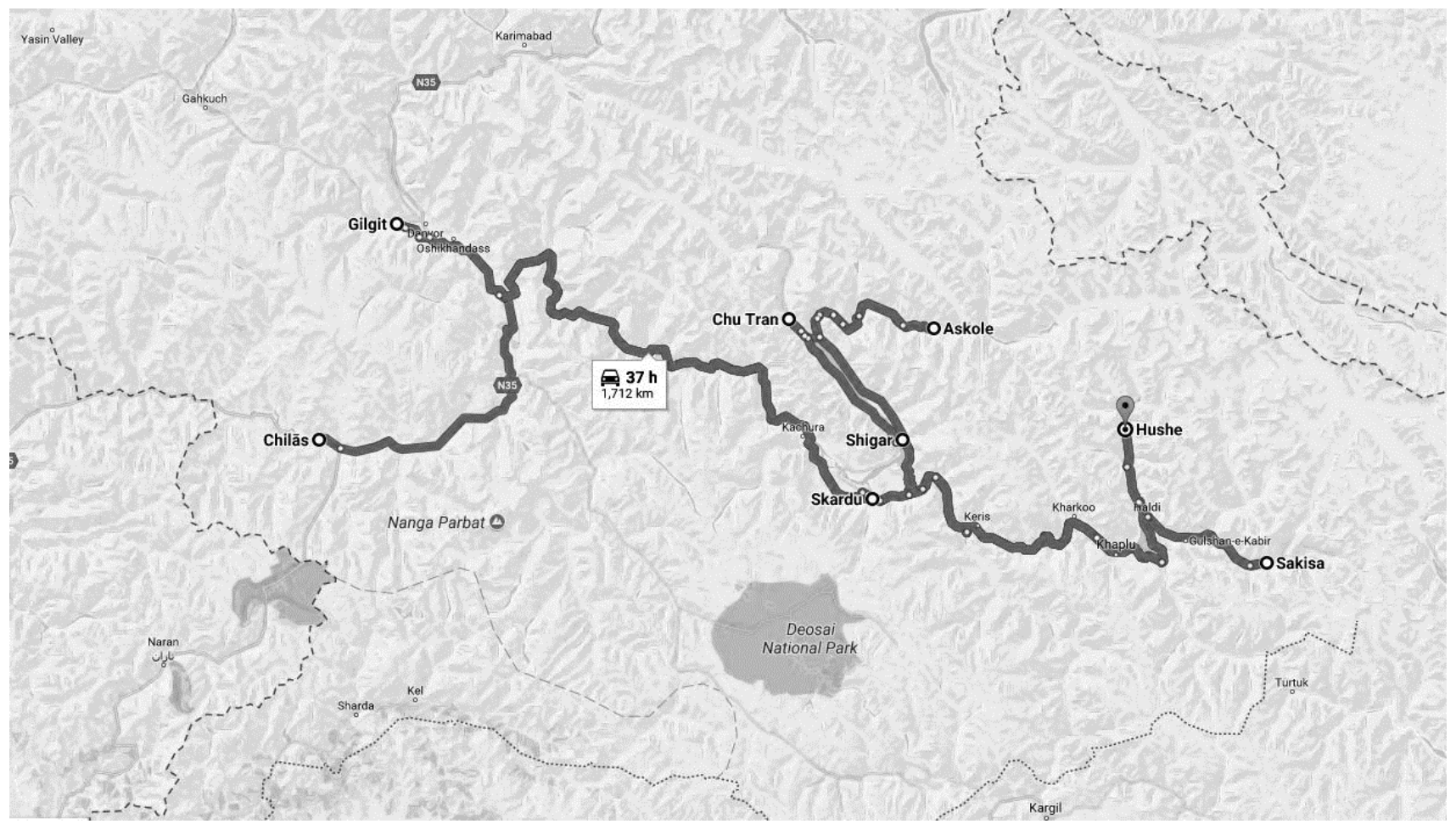

Figure 2. Field trip route in Gilgit-Baltistan (Source: Google maps).

I realised the importance of the road once I had to travel on foot from Tiser to Skardu by carrying 30 to $40 \mathrm{~kg}$ of walnuts and dried apricots. I traveled for seven days and then I reached Skardu....I rested for three days, sold the dry fruits, purchased some light goods and came back in seven days. Now we can reach Skardu in only three hours. (Adi, a porter)

Because there was no proper road, very few people used to come to Gilgit-Baltistan. 'One story is that Marco Polo went to China through this area' (Shiq). Historic evidence suggests that in 1887 Colonel Younghusband successfully attempted to cross Mustagh pass, which was closed for about fifty years due to ice advancement. The second proper attempt was made in 1903 by Aug. C.F. Feber who crossed Mustagh pass from the Askoli side and hired local guides and porters (Ferber, 1907). However, due to the installation of aviation services in Gilgit and Skardu, followed by the war of 1948, a few adventure tourists started coming to climb mountains such as K2. An Italian expedition visited Skardu in 1954 and successfully summitted K2 for the first time. This laid the foundation of mountaineering in the history of Gilgit-Baltistan.

Furthermore, only traditional healthcare treatments were practised, and medics were rarely available to everyone because of travel constraints (Asrat, Han). Similarly, there were no formal education facilities available. People had to migrate to cities to seek education, which is why very few people had access to education (Shiq, Herbaz, Amel).

The completion of the road in 1978 opened a new window in the history of Gilgit-Baltistan by providing an easy opportunity for the people of Gilgit-Baltistan to travel beyond their immediate geographies. Meanwhile, the road removed the sense of isolation, inaccessibility and travel constraints and provide an opportunity for outsiders to explore this remote region. Such physical mobilities provided an extraordinary prospect for both hosts and guests to learn from each other by connecting GilgitBaltistan with the outside world which resulted in social inclusion. Road infrastructure developed in the last three decades has altered the lives and livelihood of these people in significant ways. There has also been a significant increase in awareness about different aspects of life due to the arrival of numerous vehicles.

According to one participant (Hsan, a transport representative), the painful act of carrying heavy loads on backs has come to an end and deliveries are made to your doorstep. In addition to the food and material goods delivered by the road, the new infrastructure also brings changes from the outside through exchange of culture, education and language (Hah, a non-government organisation representative). The road is the medium through which development has arrived and the areas have seen schools, hospitals, electricity, and markets created (Irdos, Hsan, GhulamA, Azahir, Brahim). It is reasoned that because of these facilities huge changes have occurred in the living standard of people (Hmad, a household head). A progressive change in cleanliness conditions, diet, clothing fashion, business, and education is observed (Azir, Hah, Usa, Aza, Adi).

'After the construction of the road, various people came here, we have learned Urdu and English, and about different food and clothing' (Adi, Ozi). 'Awareness about 
education has increased because of interaction with visitors as people realise the benefits as an educated man in society enjoys good social status' (Aja, a community leader). 'The road brought huge benefits for us...there was no school here...this school, the high school, the girls' school-all happened in my lifetime. This all happened just because of the road' (Adi, a porter).

There was a trend that one family member would migrate to a city such as Lahore and Rawalpindi to generate income and remit to his household which leads to a convenient and easy lifestyle' (Shraf). Some families migrated as a whole to educate their children. 'All of my family is here for the sake of education' (Asim, a community leader). However, due to improvement in roads and availability of job opportunities, such migration trends are changing.

At any one time, 8000 vehicles run on the Karakoram Highway. Thousands of passengers buy a ticket, stay in a hotel buy food etc, which makes this journey significant for people living along the Karakoram Highway (Hsan, a transport operator representative).

Increased accessibility to, and awareness of previously remote communities of Gilgit-Baltistan has, in part, led to an improvement in education and healthcare facilities due to the special interest of the government, nongovernment organisations and tourism enterprises (Hah, Shiq, Hanna). Now, almost every union council has got a dispensary and a school (Hah, Amal, Hanna). Moreover, due to the development of transport infrastructure, people are starting new businesses, including many in the tourism sector. All new tour companies are owned and operated by young and educated local people who see tourism as the primary source of income for GilgitBaltistan (Asharat, Adpara, Aba).

\subsection{Perceived Impacts of Karakoram Highway}

As discussed above, our respondents recall numerous benefits of the roads. There is a consensus among many respondents that road infrastructure has resulted in increased tourism as compared to the past. Before roads were built, people used to carry loads to meet their basic survival needs. After the transport infrastructure was improved, tourism numbers-especially mountaineers and trekkers-have increased requiring other services, such as porter facilities. This demand for porters attracted people from subsistence farming to a monetary economy. Now, carrying a load has become the means of making a living for the majority of the people of our study setting.

'Tourism has become the source of income and now we have a government tourism department. In tourist destinations like Askoli and Hushe, more than $90 \%$ of the people are affiliated with tourism' (Azahir). Household heads argue that because of poverty and instant payment by tourists, more people started working as porters (Hanna, Azahir, Aved). Months of hard work in the field were replaced with a few hours of tourism labouring jobs, which would enable the workers to buy groceries (Aved, a household head). Such facilitation provided by the road and tourism has diverted people from agricultural activities (Ashraf, a shopkeeper). Now, most of the farm labour is undertaken by women while men go with tourists to earn money (Ahan, a female student). It is observed that the traditional practices of land development are not being practised anymore and the limited agricultural land is being utilised for building tourism amenities (Ohammad, Hmad, Hanna, Aved). People started developing hotels and restaurants which have provided numerous job opportunities and transportation services have facilitated travel which is easy and fast (Aba, a tour operator). These changes have facilitated social inclusion with the outside world by enabling contact with visitors and through the purchase of goods, which provide other forms of contact, with the money earned from tourists.

Furthermore, a transport operator (Hsan) argued that 'when foreign tourists visit, they buy food, handicrafts, and stay in a guest house, which benefits many local people'. Lots of markets have formed, colleges have been established, people came and the tourism industry has improved, expeditions came. Lots of healthcare facilities came here because of the formation of the Karakoram Highway (Irdos, a contractor).

'Many tourists come as volunteer teachers and people have learnt many things from them. Tourists have educated many people here. Some stayed...for two to three years' (Amid, a tour operator). A tourist has opened a hospital in Arando and she sends medicines regularly (Ustafa, a porter). Working with tourists and interaction with tourists have made people self-sustained financially and affected traditional lifestyles. It is believed that people are not dependent on anyone because of tourism (laz, camp manager).

It is believed that use of mobile phones and other electronic devices have caused social inclusion with cities, which was possible after the formation of roads.

Earlier, to contact a Gora (tourist) and ask about their program (arrival) we used to go to Skardu [150km away]. If we had to send an email, then we had to go to Rawalpindi [770km away]. Now, we can contact them from here [Hushe]. (Ozi, a guide, and household head)

However, it is argued by many respondents that strategically located Gilgit-Baltistan is a land lock region and the Karakoram Highway is the only way in and out which has made people dependent on the highway. For instance, after the completion of the Karakoram Highway project, residents of Gilgit-Baltistan were given a subsidy on nine consumer goods including wheat, sugar, and oil. Government and community organisation representatives argue that such subsidies have diverted the concentration of people from agriculture towards services or wage earnings. Money earned and spent on goods was consid- 
ered as an easy option compared to farming (Asharat, a hotel owner). Government representatives believe that the people's dependency on the Karakoram Highway has made them vulnerable as the Highway is prone to natural and manmade disasters.

If the road is blocked there will be a shortage of food items. Our dependency is on the Karakoram Highway and there is no place else all vegetable shops are closed...we conducted a survey PKR 1.5 billion worth of dairy products comes into Gilgit from down country in one year. (Azir, planning commission representative)

Because of the blockade of the road for two or three days, many types of problems took place, which includes the problem of gas, flour, eatable...You can say that this Karakoram Highway is a lifeline for GilgitBaltistan. (Hsan, a transport operator representative)

Government and community organisation representatives argue that Gilgit-Baltistan can be self-sufficient by irrigating barren land and there will be no need for subsidies. According to one estimate, the population density of Gilgit-Baltistan is 10-12 households per square kilometer and only $0.01 \%$ of the land is cultivable out of 72,000 square kilometers. Furthermore, houses, shops, and plazas are now being built on that $0.01 \%$ of the land. That land is being divided among siblings and no one has developed new land (Asir, representative of planning and development). Community organisation sources claim that $1.5 \%$ land is usable. However, there is a consensus that the land can be developed with little effort (Asir, Alman). The sense of community has been lost which was driving force for agricultural land development for community's wellbeing.

No new water channel has been made in Gilgit since the formation of two historic water channels by Dadi Jawari around 700 years ago. There is no such scheme in the Annual Development Plan. Which is why agricultural land is diminishing and we are becoming more dependent. (Asir, representative of planning and development)

Furthermore, there was acknowledgment among participants that the road has altered the peace in the area as residents previously belonged to a single ethnic group and there was a local governance system (Han). It is also believed that roading infrastructure has caused many social transformations. People of Baltistan, in older times, were simple and trusting but now people are becoming clever after observing people in cities (Sghar, a porter). There has been a decrease in love, respect, and relationships (Sghar, Isar). The old sense of community in isolated villages is being diminished with the arrival of the highway. Connection and inclusion with the outside world could have a social impact on support from within the community during times of crisis. This explains the idea of simultaneous reduction of inclusion at one scale alongside an increase at another scale.

In addition to the many acknowledged benefits of the road, participants recognised important changes in culture, including consumption patterns. 'There was no concept of lunch at $12 \mathrm{pm}$. We only used to eat two times a day, breakfast and dinner. Now, everything has changed' (GhulamH, community leader).

Before the road, we used to eat Khachi, Summa (simple local dishes, without spices), dried vegetables, and apricot meals. Now, all of those things are gone. Now, everyone makes sweet and salty tea and all sorts of vegetables. Things which are common in cities have arrived here and there has been a lot of change in what we eat. (Hmed, a household head)

It is believed that road has brought in change from outside and influenced our culture (Ozi, Azahir). Traditional dresses are being replaced with modern dresses. One can buy a quality dress for PKR 150 (Her, a cook) and 'people do not wear woollen clothes anymore, instead, they wear Pants-Shirt (European clothing) and ShalwarKameez (Pakistani clothing) (laz, camp manager).

Outsiders came here, and we went there and saw different dresses and we got influenced. If tomorrow, this road to Ladakh and Kashmir is opened we will see Ladakhi culture here and you will see Gilgit-Baltistan culture in Ladakh. Look at the people of Hunza. Because of trade with China, they are adopting Xinjiang culture. (Azmi, a community leader)

By observing different cultures and interacting with people it is argued that local culture is dying, an obvious negative impact of roads noted by many respondents. A non-government organisation representative argues that change is part of the development and that that the loss of some of the old traditions is not altogether bad (Asool).

\section{Conclusion}

The Karakorum Highway has resulted in profound changes to Gilgit-Baltistan. Communities that were once isolated and insular have now become integrated with the outside world. Consequently, there has been a major shift in how social inclusiveness can be viewed. As discussed above there has been a transformation in income, employment, political participation and citizenship, access to transport, education, healthcare, and availability of goods and services. In contrast to research on social inclusion in the developed world, the ramification of roads in isolated regions can be viewed quite differently, at least in the early stages of changing societies. Rather than disadvantaged people feeling socially excluded by being at the end of a road, having a road at all provides 
a sense of social inclusion with the rest of the world. Furthermore, while some of the local population do not own modern electrical technology, they do not suffer the degree of exclusion reported in the literature. This is because they have access to the technology. They know people within the community who own these things and are able to use them. Visitors, whether they are domestic working tourists or international recreational tourists, add to that sense of inclusion. Similarly, the increased wealth that visitors provide for local people increases the sense of social inclusion. This may be due to a stronger sense of community within the villages of Gilgit-Baltistan that has yet to break down into individualistic attitudes of the West. The obvious question that arises from this is whether Gilgit-Baltistan is in a transitional phase from a traditional subsistence economy to a consumerist society where social inclusion and exclusion is a result of wealth, health, and access, or whether forms of social inclusion and exclusion are culturally based. The examples from Nepal, which has been going through the changes described here for a longer period, seem to suggest that it is cultural, but that is still a moot point.

\section{Acknowledgments}

We would like to acknowledge the assistance of individuals during fieldwork. Without their support and guidance, it would have been very hard to complete this task on time. We express our appreciation and gratitude for their efforts.

\section{Conflict of Interests}

The authors declare no conflict of interests.

\section{References}

Ali, W. (2017, August 31). Gilgit-Baltistan Census 2017. Daily Express.

Anderson, B., \& Tracey, K. (2001). Digital living: The impact (or otherwise) of the Internet on everyday life. American behavioral scientist, 45(3), 456-475.

Atkinson, A. B., \& Hills, J. (1998). Exclusion, employment and opportunity.

Barry, B. M. (1998). Social exclusion, social isolation and the distribution of income. London: Centre for Analysis of Social Exclusion, London School of Economics.

Burchardt, T., Le Grand, J., \& Piachaud, D. (1999). Social exclusion in Britain 1991-1995. Social Policy \& Administration, 33(3), 227-244.

Church, A., Frost, M., \& Sullivan, K. (2000). Transport and social exclusion in London. Transport Policy, 7(3), 195-205.

CoMPRIS. (1998). The information society: Issues and opportunities. Yorkshire \& Humberside, RAYH (Regional Assembly for Yorkshire \& Humberside GOYH (Government Office for Yorkshire and the Humber). Retrieved from http://www.compris.co.uk
Currie, G., \& Delbosc, A. (2010). Modelling the social and psychological impacts of transport disadvantage. Transportation, 37(6), 953-966.

Currie, G., Stanley, J., \& Stanley, J. (2007). No way to go: Transport and social disadvantage in Australian communities. Melbourne: Monash University ePress.

Denzin, N. K., \& Lincoln, Y. S. (2008). Handbook of critical and indigenous methodologies. Sage.

Espiner, S., Stewart, E. J., \& Lama, L. T. (2017). Assessing the effectiveness of 'Appreciative Inquiry'(AI) in Nepali pro-poor tourism (PPT) development processes. Tourism Planning \& Development, 14(3), 369-388.

Ferber, A. C. (1907). An exploration of the Mustagh Pass in the Karakoram Himalayas. Geographical Journal, 630-643.

Folwell, K. (1999). Getting the measure of social exclusion. London: Research Centre London.

Garrison, W., \& Souleyrette, R. (1996). Transportation, innovation, and development: The companion innovation hypothesis. Logistics and Transportation review, 32(1), 5.

Gill, N., Caletrío, J., \& Mason, V. (2011). Introduction: Mobilities and forced migration. Mobilities, 6(3), 301-316.

Goulding, C. (2002). Grounded theory: A practical guide for management, business and market researchers. Sage.

Gurung, L. (2012). Exploring links between tourism and agriculture in sustainable development: A case study of Kagbeni VDC, Nepal. Lincoln University.

Hannam, K. (2006). Tourism and development III: Performances, performativities and mobilities. Progress in Development Studies, 6(3), 243-249.

Hannam, K., Butler, G., \& Paris, C. M. (2014). Developments and key issues in tourism mobilities. Annals of Tourism Research, 44, 171-185.

Harrison, D. (2001). Tourism and the less developed world: issues and case studies. Cabi.

Helsper, E. (2008). Digital inclusion: An analysis of social disadvantage and the information society. Department for Communities and Local Government.

Hussain, A. (2017). Transport infrastructural development and livelihood: A case of adaptation and diversification strategies in the face of tourism. Paper presented at CAUTHE 2017: Time For Big Ideas? Rethinking The Field For Tomorrow.

Hussain, K. (2016). Experience and status of tourism in Gilgit-Baltistan. Tourism, Youth Affairs, Sports and Culture Department Government of Gilgit Baltistan, Aga Khan Rural Support Program Skardu, Baltistan Division.

Kenyon, S., Lyons, G., \& Rafferty, J. (2002). Transport and social exclusion: Investigating the possibility of promoting inclusion through virtual mobility. Journal of Transport Geography, 10(3), 207-219.

Khalid, B. M. M. (2006). History of Karakoram Highway (Vol. 1). Rawalpindi: Hamza Pervez Printers. 
Kreutzmann, H. (1991). The Karakoram Highway: The impact of road construction on mountain societies. Modern Asian Studies, 25(4), 711-736.

Kreutzmann, H. (2004). Accessibility for High Asia: Comparative perspectives on northern Pakistan's traffic infrastructure and linkages with its neighbours in the Hindukush-Karakoram-Himalaya. Journal of Mountain Science, 1(3), 193-210.

Kreutzmann, H. (2015). Boundaries and space in GilgitBaltistan. Contemporary South Asia, 23(3), 276-291.

Lakshmanan, T., \& Chatterjee, L. R. (2005). Economic consequences of transport improvements. ACCESS Magazine, 1(26).

Levitas, R., Pantazis, C., Fahmy, E., Gordon, D., Lloyd, E., \& Patsios, D. (2007). The multi-dimensional analysis of social exclusion. Bristol: University of Bristol.

Litman, T. (2003). Social inclusion as a transport planning issue in Canada. Victoria Transport Policy Institute, 1.

Lucas, K. (2012). Transport and social exclusion: Where are we now? Transport Policy, 20, 105-113.

MOAC. (2001). Ministry of Agriculture and Cooperatives. Retrieved from http://www.moac.gov.np/index.php

MoTCA. (2010). Tourism Statistics Kathmandu Nepal. Kathmandu: Ministry of Tourism and Civil Aviation. Retrieved from http://www.tourism.gov.np/ page. php?nav=30

Nepal, S. (2005). Tourism and remote mountain settlements: Spatial and temporal development of tourist infrastructure in the Mt Everest region, Nepal. Tourism Geographies, 7(2), 205-227.

Olsson, J. (2009). Improved road accessibility and indirect development effects: Evidence from rural Philippines. Journal of Transport Geography, 17(6), 476-483.

Oswin, N., \& Yeoh, B. S. (2010). Introduction: Mobile city Singapore. Mobilities, 5(2), 167-175.

Owen, W. (1959). Transportation and economic development. The American Economic Review, 49(2), 179-187.

Pakistan, G. o., \& IUCN. (2003). Northern Areas strategy for sustainable development. Karachi: IUCN Pakistan.

Patton, M. Q. (2002). Two decades of developments in qualitative inquiry a personal, experiential perspective. Qualitative Social Work, 1(3), 261-283.

Percy-Smith, J. (2000). Policy responses to social exclusion: Towards inclusion? Maidenhead: McGraw-Hill Education.

Peters, D. (2000). Old myths and new realities of transport infrastructure assessment: Implication for EU Interventions in Central Europe. In Transport projects, programmes and policies. Farnham: Ashgate.

Phipps, L. (2000). New communications technologies: A conduit for social inclusion. Information, Communication \& Society, 3(1), 39-68.

Rana, A. u. R. (2014). Position paper for draft tourism policy: Gilgit-Baltistan. Washington, DC: USAID FIRMS PROJECT.

Ricci, M., Parkhurst, G., \& Jain, J. (2016). Transport policy and social inclusion. Social Inclusion, 4(3), 1-6.

Richardson, T. (2013). Borders and mobilities: Introduction to the special issue. Mobilities, 8(1), 1-6.

Ritchie, J. (2013). The application of qualitative methods to social research. In J. Ritchie, J. Lewis, C. M. Nicholls, \& R. Ormston (Eds.), Qualitative research practice: A guide for social science students and researchers (pp. 24-46). London: Sage.

SEU. (2003). Making the connections: Final report on transport and social exclusion. London: Social Exclusion Unit.

Snape, D., \& Spencer, L. (2011). The foundation of qualitative research. In Qualitative research practice (A guide for students and researchers) (pp. 1-23). London: Sage.

Spiggle, S. (1994). Analysis and interpretation of qualitative data in consumer research. Journal of consumer research, 21(3), 491-503.

Wachs, M., \& Kumagai, T. G. (1973). Physical accessibility as a social indicator. Socio-Economic Planning Sciences, 7(5), 437-456.

\section{About the Authors}

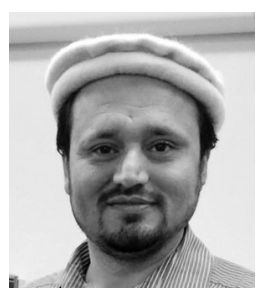

Asif Hussain is PhD candidate at Lincoln University, New Zealand. His core focus is the consequences of transport infrastructure development on livelihood diversification and adaptation strategies in tourism contexts.

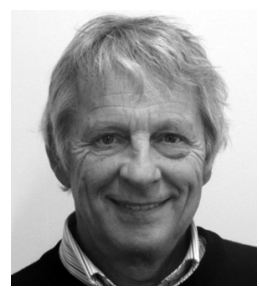

David Fisher is a Senior Lecturer in Tourism at Lincoln University, New Zealand. His research interests include heritage tourism and tourism theory. He is currently working on the conceptualisations of time in tourism. 


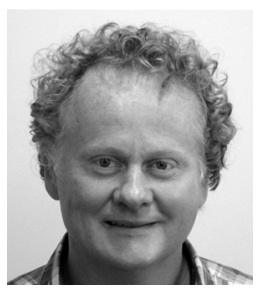

Stephen Espiner is a Senior Lecturer in Parks, Recreation and Tourism at Lincoln University New Zealand. His current research interests focus on the human dimensions of protected natural area management, with particular reference to nature-based recreation and tourism and associated conservation, community and visitor management issues. 